\title{
Anterior Segment Optical Coherence Tomography (AS-OCT) Guided Reversal of Edematous Punctal Occlusion
}

This article was published in the following Dove Press journal: Clinical Ophthalmology

\section{Mohammed Sameh Elshorbagy Osama E Shalaby (D) Mohamed Ashraf Eldesouky Amr M Awara iD \\ Oculoplasty Unit, Ophthalmology Department, Tanta University, Tanta, Egypt}

Correspondence: Amr M Awara Oculoplasty Unit, Ophthalmology Department, Tanta University, Tanta 315II, Egypt

Tel +20 1274005384

Fax +20 4034I5008

Email amrawara@gmail.com

\begin{abstract}
Aim: To evaluate the role of anterior segment-optical coherence tomography (AS-OCT) in the diagnosis of punctal stenosis and to compare punctal parameters before and after medical treatment.
\end{abstract}

Patients and Methods: The study was conducted on 40 eyes of 24 patients who had acquired inflammatory punctal stenosis and had persistent epiphora (persistent epiphora group - PEG), and 20 eyes of 10 subjects with normal punctal openings as a control group (control group - CG). We measured the outer punctal diameter (OPD), recorded the visibility of the internal punctum and punctal depth (PD) using AS-OCT, before and 1 month after treatment with preservative free methylprednisolone 5\% eye drops. Punctal diameter, tear meniscus height (TMH) and Munk's score were compared to the control group before and after treatment.

Results: The mean OPD of the PEG before treatment $(455.5 \pm 174 \mu \mathrm{m})$ was significantly smaller than that of the CG $(590.9 \pm 106.6 \mu \mathrm{m})(P=0.002)$. The mean OPD of the PEG significantly increased to $484.6 \pm 175.5 \mu \mathrm{m}$ after treatment $(P<0.001)$. Also, the visibility of vertical canaliculus lumen and PD were restored in $70 \%$ of eyes. The TMH was much higher in the PEG than in the CG before treatment $(P<0.05)$. However, after treatment the difference was not statistically significant.

Conclusion: AS-OCT parameters were useful in monitoring and measuring the efficacy of medical treatment in relieving punctal edema, which subsequently resulted in reducing the epiphora symptoms.

Keywords: AS-OCT, punctal occlusion, punctal edema, preservative-free steroids

\section{Introduction}

Punctal stenosis is an important etiological factor that should be considered when assessing patients with epiphora. Anatomically, acquired punctal stenosis is a condition in which the external opening of the lacrimal canaliculus is narrowed or occluded and also can be accompanied by canalicular ductal stenosis. ${ }^{1,2}$. Defining an anatomical clear cut-off value for punctal stenosis is difficult due to wide variations in patients' demographics. Clinically, punctal stenosis is defined as a punctum size restricting tear drainage in the absence of distal tear drainage abnormalities. ${ }^{2}$

Acquired punctal stenosis can be involutional, inflammatory, infectious or idiopathic." ${ }^{3,4}$ Inflammatory endogenous causes include chronic blepharitis, dry eye disease and ocular cicatricial pemphigoid. ${ }^{3}$ Exogenous noxious stimuli may be chemical such as topical or systemic medications, or physical as irradiation or 
mechanical. The harmful effect of topical medications such as antiglaucomatous drops, dexamesathone, mitomycin-C and the systemic medications such 5-Fluorouracil or paclitaxel may be related to the medication themselves, the preservatives as benzalkonium chloride in the commercial preparations, or duration of treatment with those medications. ${ }^{3,5-9}$ The basic ultra-structure response to those various noxious stimuli is early punctal occlusion by edema which is followed by conjunctival overgrowth, keratinization of punctal walls and cicatricial punctal stenosis.

Although spectral-domain OCT is still being widely used on the retina, its anterior segment module is considered a new modality for imaging of proximal lacrimal excretory passage and tears meniscus height (TMH).

Recent studies showed the ability of using AS-OCT to differentiate between various punctal causes of epiphora and improve the understanding of the lacrimal punctal structure in vivo. ${ }^{10-12}$

The aim of this work is to evaluate the role of AS-OCT in the diagnosis of punctal edematous stenosis by imaging, monitoring and comparing punctal parameters between patients and control subjects before and after treatment with preservative-free steroid eye drops in patients with persistent epiphora due to inflammatory punctal stenosis.

\section{Patients and Methods}

This was a prospective study that included 40 eyes of 24 patients, who had acquired punctal stenosis and persistent epiphora (PEG). Patients were selected from the outpatient clinic in the Department of Ophthalmology; Tanta University Hospitals, between September 2018 and September 2019. Patients were chosen from those aged 21 years or more who had acquired inflammatory punctal edema and were complaining of epiphora. Those with congenital punctal anomalies, history of previous lacrimal surgery or trauma or those who had lower lid margin malposition or laxity were excluded. Twenty eyes of punctal disease-free controls (CG), who were age- and sexmatched were also included to be compared to the patients. The participants in CG were tested for dry eye by Schirmer test before the study and any subject with positive results for dry eye were excluded. After discussing the study's aim and intervention details, an informed written consent was obtained from all the participants before inclusion. The study was approved by the ethical committee of Tanta University Hospital and was performed according to the Declaration of Helsinki.

\section{Methods}

\section{Routine Clinical Examination}

All patients were assessed using a standard protocol that included:

(A) Detailed history, especially of using medications for ophthalmic or systemic diseases, epiphora grading by Munk's score ${ }^{13}$ and complete ophthalmological examination. Moreover, special attention was paid to the tear meniscus, lid margin, conjunctiva around the punctum, and intraocular pressure measurement.

(B) Punctum evaluation:

1. By slit lamp for visibility, shape and presence of inflammation or edema.

2. By Topcon 3D Spectral Domain AS-OCT-2000 series: outer punctal diameter (OPD), visibility of vertical canalicular lumen and punctal depth (PD) were assessed.

\section{Measuring Technique}

Lower eyelid margin was everted using a cotton bud that was placed below the punctum, for gentle eversion whilst avoiding distortion or compression. The punctum was everted into a plane perpendicular to the light source to allow alignment of the punctum and canaliculus with respect to the axis of the scanner's infrared beam. The punctum was imaged with the scan line placed horizontally along the mucocutaneous junction. OPD was measured as the distance between the highest points on the nasal and temporal punctal orifice (Figure 1). PD is the vertical canalicular lumen; it was measured vertically between outer and inner punctal openings also angulation of the medial and lateral ductal walls towards the inner punctum was assessed. The inner punctal opening is an area where the punctum appears narrowed/closed.

Preservative-free steroids in the form of methylprednisolone $5 \%$ eye drops were prepared by dilution of methylprednisolone $500 \mathrm{mg}$ in $10 \mathrm{~mL}$ distilled water (Solumedrol, Pfizer company, NY, USA), and given for all enrolled cases to use 5 times a day for 5 days with gradual tapering over the subsequent 2 weeks, followed by preservative-free tear substitute eye drops (sodium hyaluronate) 3 times a day for 2 weeks. Patients were re-examined clinically and by AS-OCT 1 month after treatment. AS-OCT measurements were taken by the same experienced operator and on the same machine to avoid inter-observer variability. 

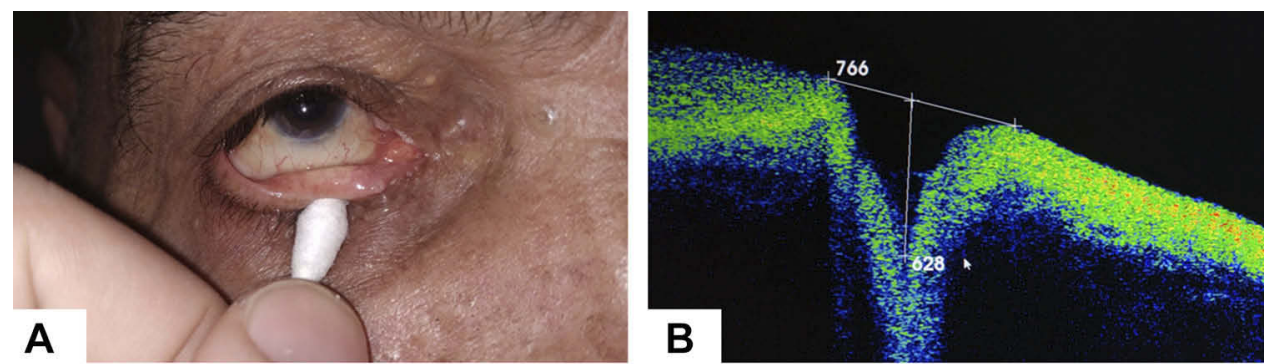

Figure I Measuring technique: (A) Lower eyelid margin was everted using a cotton bud into a plane perpendicular to the light source. (B) Anterior segment optical coherence tomography (AS-OCT) image showing punctal parameters (outer punctal diameter (OPD), internal punctum and punctal depth (PD)) of a participant in the control group that was measured using anterior segment module of Topcon 3D OCT-2000 TM (Topcon Medical Systems Inc.).

\section{Statistical Analysis}

Data were analyzed using SPSS version 25 (IBM Corporation, Armonk, NY, USA). Furthermore, the qualitative parameters were described as frequency and percentage while the quantitative variables were described in terms of mean, standard deviation and range. Comparison of two dependent quantitative variables was calculated by paired $t$-test while the comparison of two independent quantitative variables was calculated by independent Students' $t$-test.The comparison between two qualitative variables was done by Chi-square $\left(\chi^{2}\right)$ test and whenever any of the expected cells were less than five, Fischer's Exact test was used. Two sided $P$-value $<0.05$ was considered statistically significant.

\section{Results}

PEG and CG were age- and gender-matched with no significant difference between them (Table 1).

\section{Before Treatment}

Among the PEG, 16 (66.7\%) patients had bilateral and 8 $(33.3 \%)$ had unilateral punctal stenosis. Clinical history of

Table I Age and Gender Distribution of the Two Studied Groups

\begin{tabular}{|c|l|l|l|}
\hline Variable & $\begin{array}{l}\text { PEG (n=24 } \\
\text { Patients) } \\
\text { No. (\%) }\end{array}$ & $\begin{array}{l}\text { CG (n=10 } \\
\text { Patients) } \\
\text { No. (\%) }\end{array}$ & P-value \\
\hline $\begin{array}{c}\text { Gender } \\
\text { Male }\end{array}$ & $3(12.5)$ & $2(20.0)$ & 0.573 \\
Female & $21(87.5)$ & $8(80.0)$ & \\
\hline $\begin{array}{c}\text { Age group } \\
\text { 25-34 years }\end{array}$ & $1(4.1)$ & I (10.0) & 0.925 \\
$35-44$ years & $3(12.5)$ & I (10.0) & \\
45-54 years & $8(33.3)$ & $3(30.0)$ & \\
$55-64$ years & $12(50.0)$ & $5(50.0)$ & \\
\hline
\end{tabular}

Abbreviations: PEG, persistent epiphora group; CG, control group. chronic use of eye drops was present in 20 eyes (50\%), that included combined antibiotic-steroid ( $\mathrm{n}=12$ eyes), ocular hypotensive $(\mathrm{n}=4)$ and decongestants $(\mathrm{n}=4)$. Twenty eyes (50\%) had chronic blepharitis while 8 $(17.5 \%)$ had history of cataract surgery $(17.5 \%)$ and 2 $(5 \%)$ of systemic chemotherapy.

On slit lamp examination of the PEG, 30 eyes (75\%) had punctal edema (stuffed punctum appearance), 19 eyes (63.3\%) pinpoint and 11 eyes (36.7\%) slit lumen shape while $10(25 \%)$ had edema with barely recognizable punctal orifices (membranous occlusion).

The TMH in 24 eyes $(60 \%)$ of the PEG was more than $0.4 \mathrm{~mm}$ and in 16 eyes (40\%) was less than $0.4 \mathrm{~mm}$, while all the eyes in the CG had TMH less than $0.4 \mathrm{~mm}$ with a statistically significant difference between the two groups (P 0.001).

OPD measurements (Table 2) showed that the PEG had significantly smaller OPD than the control group $(P=0.002)$. Punctal depth and angulation of the medial and lateral walls towards the inner punctum (canalicular lumen) were totally lost in all cases of the PEG.

\section{After Treatment}

One month after treatment of the patients in the PEG, a significant improvement of symptoms occurred, evaluated by Munk's score $(P<0.001)$ (Figure 2).

Table 2 Comparison of the PEG and the CG Before Treatment Regarding OPD

\begin{tabular}{|c|c|c|c|}
\hline & $\begin{array}{l}\text { PEG ( } n=40 \text { Eyes) } \\
\text { Mean } \pm \text { SD } \\
\text { Range }\end{array}$ & $\begin{array}{l}\text { CG ( } n=20 \text { Eyes) } \\
\text { Mean } \pm \text { SD } \\
\text { Range }\end{array}$ & $P$-value \\
\hline OPD $(\mu \mathrm{m})$ & $\begin{array}{l}455.5 \pm 173 \\
206.0-701.0\end{array}$ & $\begin{array}{l}590.0 \pm 106.6 \\
437.0-766.0\end{array}$ & 0.002 \\
\hline
\end{tabular}

Abbreviations: PEG, persistent epiphora group; CG, control group; OPD, outer punctal diameter. 


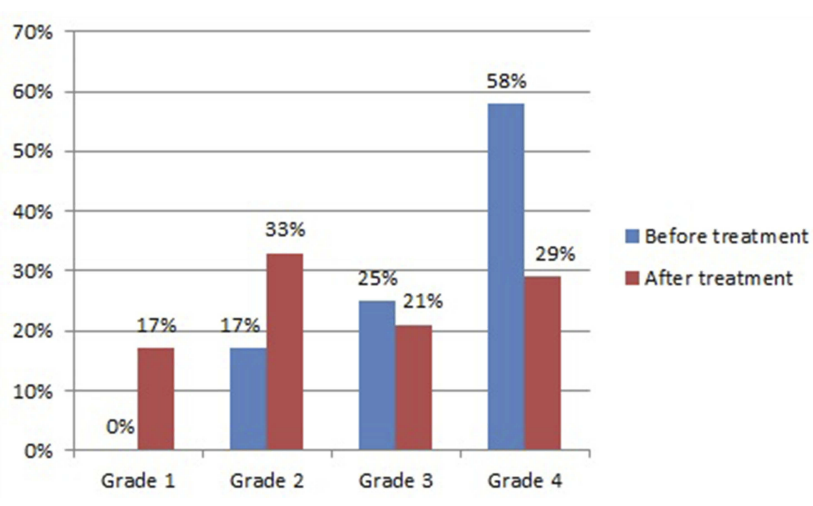

Figure 2 Epiphora grading by Munk's score among persistent epiphora group (PEG) before and I month after treatment showed significant improvement of epiphora symptoms after treatment.

Slit lamp examination showed that 28 eyes $(70 \%)$ in the PEG had decreased punctal edema with widening of punctal opening, while 12 eyes (30\%) still had the punctal opening barely visible with marked occlusion. Concerning the $\mathrm{TMH}$, there was no statistically significant difference between the $P E G$ and the $C G$ $(P=0.19)$.

OPD in the PEG was significantly increased after 1 month of preservative-free steroid eye drops $(P<0.05)$ (Table 3$)$.

Punctal depth and ductal wall angulation were restored in $70 \%$ of eyes (28 eyes) following treatment $(P<0.001)$; whereas in $30 \%$ of eyes (12 eyes), it could not be restored (Figures 3 and 4).

\section{Discussion}

Both chronic blepharitis and long-term use of topical antiglaucoma medication were the most common noxious stimuli causing punctal edema in this study. Both are wellknown predisposing factors of punctal stenosis combined with inflammatory and fibrotic changes in the lining epithelium and stroma of the punctum. ${ }^{1,14,15}$

Table 3 Comparison Between Outer Punctal Diameter (OPD) of Persistent Epiphora Group (PEG) Before Treatment and After Treatment

\begin{tabular}{|l|l|l|l|}
\hline & Before Treatment & After Treatment & \multirow{2}{*}{ P-value } \\
\cline { 2 - 3 } & $\begin{array}{l}\text { Mean } \pm \text { SD } \\
\text { Range }\end{array}$ & $\begin{array}{l}\text { Mean } \pm \text { SD } \\
\text { Range }\end{array}$ & \\
\hline OPD $(\mu \mathrm{m})$ & $\begin{array}{l}455.5 \pm 173 \\
206-701\end{array}$ & $\begin{array}{l}484.6 \pm 175.5 \\
224-730\end{array}$ & $<0.001$ \\
& & \\
\hline
\end{tabular}

Note: The normal anatomy of the punctum varies greatly and there is scant evidence to aid in the clinical definition of what constitutes punctal stenosis. Abbreviation: OPD, outer punctal diameter.
Both medical and surgical treatment methods have been used for treatment of punctal stenosis. In this study, we used preservative-free steroid eye drops to benefit from its anti-inflammatory effect and to avoid the toxic effect of the preservatives on the ocular surface. Preservatives have been shown to induce inflammatory cytokines with subsequent subconjunctival inflammation and punctal edema. ${ }^{9}$ A favorable effect on ocular surfaces has been shown in other studies of patients with uveitis, dry eye, and after cataract surgery. ${ }^{16-18}$ Timlin et al ${ }^{11}$ showed the ability of imaging of the proximal lacrimal system, mainly the external and internal punctal diameters of the vertical part of lacrimal canaliculus using AS-OCT. Marked variations have been reported in OPD measurements. While Allam et $\mathrm{al}^{19}$ has found the mean diameter of the OPD to be $412.16 \pm 163 \mu \mathrm{m}$, Timlin et $\mathrm{al}^{20}$ reported it to be $615 \pm$ $367 \mu \mathrm{m}$. These differences might be attributed to differences in the OCT machine used and the lack of accepted standard reference points for measurements, which carries some operator-dependent variations. They also may be related to the differences in patients' demographics, eg, age, gender and ethnic background, hence the need for using a control group in our study and depending on a single OCT machine and an experienced operator for taking the measurement for all our patients. Also, we were more concerned about comparing our measured punctal parameters (OPD \& PD) before and after treatment. In the PEG group, we noticed that the maximum outer diameter was $701 \mu \mathrm{m}$ which is against anatomical definition of punctal stenosis but interestingly, imaging in these cases showed complete loss of PD. This indicated the presence of ductal edema hindering tear outflow. So far we were unable to measure internal punctal diameter after treatment; due to residual canalicular edema that interferes with accurate reliable measurement.

In this study, we have shown that the use of AS-OCT parameters were useful in monitoring and measuring the efficacy of medical treatment in relieving punctal edema, which subsequently resulted in reducing the epiphora symptoms. We have shown that the OPD was reduced compared to the control group and it increased after treatment. There were also signs of restoration of the punctal depth with patent vertical canaliculus lumen. Inability to restore these parameters after treatment meant that marked subepithelial fibrosis had happened and caused shifting from reversible inflammatory edema to irreversible fibrotic stenosis. This would require surgical intervention, eg, 3-snip or other punctal dilating surgery. 

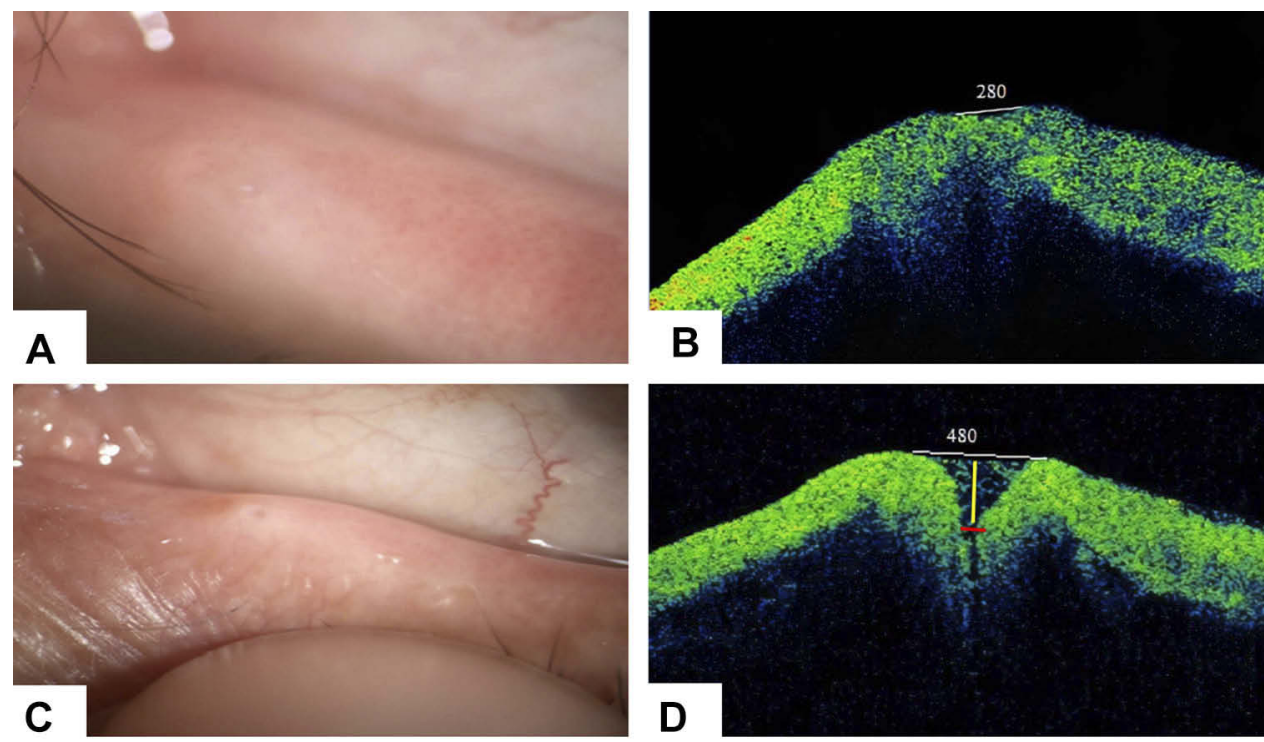

Figure 3 (A and B) Before treatment: Slit lamp examination showed barely visible punctum and stuffed appearance. Anterior segment optical coherence tomography (ASOCT) image revealed outer punctal diameter (OPD) of $280 \mu \mathrm{m}$ (white line) with lost punctal depth (PD). (C and D) One month after treatment: Slit lamp examination showed decreased punctal edema with clear visible punctal opening. AS-OCT image revealed increased OPD to $480 \mu \mathrm{m}$ (white line) and restoration of the PD (yellow line) associated with marked clinical improvement.
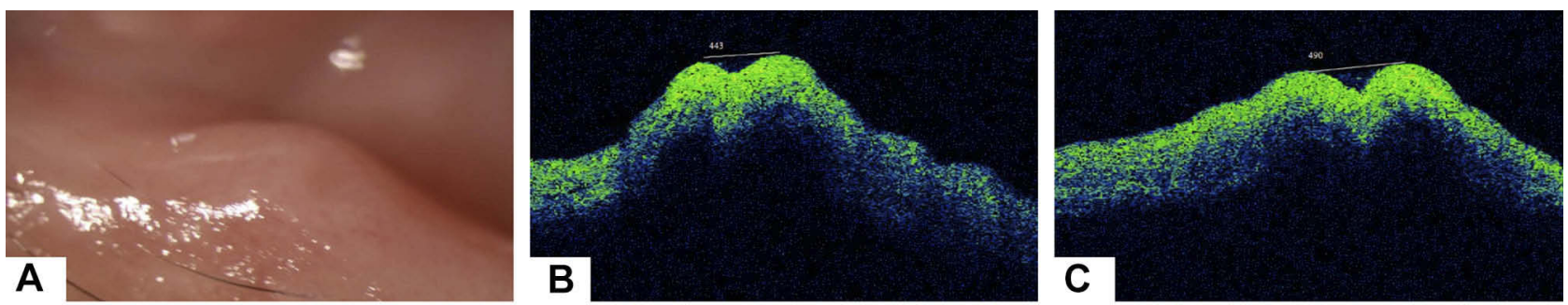

Figure 4 (A and B) Before treatment: Slit lamp examination showed barely visible punctum. Anterior segment optical coherence tomography (AS-OCT) image revealed outer punctal diameter (OPD) of $443 \mu \mathrm{m}$ (white line) with very shallow punctal depth (PD). (C) One month after treatment: AS-OCT image revealed minimal increase of OPD to $490 \mu \mathrm{m}$ (white line) meanwhile neither vertical canaliculus lumen nor inner punctal opening was restored.

In this study, we could not determine by AS-OCT whether the cause of loss of punctal depth was due to canalicular edema or fibrosis and had to rely on response or lack of response to treatment to ascertain what the cause was.

The use of OCT in assessing punctal stenosis is limited by the lack of standard normative data for comparison. We used the control group to overcome that and were able to show that in patients almost all parameters were reduced compared to the $\mathrm{CG}$ and that they were restored to normal values after treatment.

Also, there is a need for a consensus on the reference points of measurements to enhance the repeatability and reduce variability in future studies. Minimizing variability and enhancing repeatability may be achievable by using fixed anatomical landmarks, eg, posterior lid margin and using single machine and operator to take the measurements. The penetrance of the OCT is also another limiting factor for detailed assessment of the drainage system structure and function, something that may improve in future versions of the current machines.

\section{Conclusion}

AS-OCT can be useful in assessing the OPD and the PD. Its parameters were useful in monitoring and measuring the efficacy of medical treatment in relieving punctal edema, which subsequently resulted in reducing the epiphora symptoms.

\section{Disclosure}

The authors report no conflicts of interest in this work.

\section{References}

1. Hur M, Jin S, Roh M, et al. Classification of lacrimal punctal stenosis and its related histopathological feature in patients with epiphora. Korean J Ophthalmol. 2017;31(5):375-382. doi:10.3341/kjo.2016.0129 
2. Soiberman U, Kakizaki H, Selva D, Leibovitch I. Punctal stenosis: definition, diagnosis, and treatment. Clin Ophthalmol. 2012;6:10 11-1018. doi:10.2147/OPTH.S31904

3. Kashkouli MB, Beigi B, Murthy R, Astbury N. Acquired external punctal stenosis: etiology and associated findings. Am J Ophthalmol. 2003;136(6):1079-1084. doi:10.1016/S0002-9394(03)00664-0

4. Kristan RW. Treatment of lacrimal punctal stenosis with a one-snip canaliculotomy and temporary punctal plugs. JAMA Ophthalmol. 1988;106(7):878-879.

5. McNab AA. Lacrimal canalicular obstruction associated with topical ocular medication. Aust N Z J Ophthalmol. 1998;26(3):219-223. doi:10.1111/j.1442-9071.1998.tb01315.x

6. Kopp ED, Seregard S. Epiphora as a side effect of topical mitomycin C. Br J Ophthalmol. 2004;88(11):1422-1424. doi:10.1136/bjo.2004. 048033

7. Brink HM, Beex LV. Punctal and canalicular stenosis associated with systemic fluorouracil therapy. Doc Ophthalmol. 1995;90(1):1-6. doi:10.1007/BF01203288

8. McCartney E, Valluri S, Rushing D, Burgett R. Upper and lower system nasolacrimal duct stenosis secondary to paclitaxel. Ophthalmic Plast Reconstr Surg. 2007;73(2):170-171. doi:10.1097/ IOP.0b013e318032e 908

9. Epstein SP, Chen D, Asbell PA. Evaluation of biomarkers of inflammation in response to benzalkonium chloride on corneal and conjunctival epithelial cells. J Ocul Pharmacol Ther. 2009;25(5):41 5-424. doi:10.1089/jop.2008.0140

10. Sung Y, Park J, Lew H. Measurement of lacrimal punctum using spectralis domain anterior optical coherence tomography. Acta Ophthalmol (Copenh). 2017;95(7):e619-e624. doi:10.1111/aos.13322

11. Timlin HM, Keane PA, Rose GE. Characterizing the occluded lacrimal punctum using anterior segment optical coherence tomography. Ophthalmic Plast Reconstr Surg. 2018;34(1):26-30. doi:10.1097/ IOP.0000000000000840
12. Timlin HM, Keane PA, Day AC, et al. Characterizing the lacrimal punctal region using anterior segment optical coherence tomography. Acta Ophthalmol. 2016;94(2):154-159. doi:10.1111/aos.12906

13. Munk PL, Lin DT, Morris DC. Epiphora: treatment by means of dacryocystoplasty with balloon dilation of the nasolacrimal drainage apparatus. Radiology. 1990;177(3):687-690. doi:10.1148/radiology. 177.3.2243969

14. Bukhari A. Prevalence of punctal stenosis among ophthalmology patients. Middle East Afr J Ophthalmol. 2009;16(2):85-87. doi:10. 4103/0974-9233.53867

15. Baudouin C, Liang H, Labbé A, Pauly A. Preservatives in eyedrops: the good, the bad and the ugly. Prog Retin Eye Res. 2010;29(4):312-334.

16. Hedayatfar A, Hashemi H, Asgari S, Chee S-P. Comparison of efficacy and ocular surface toxicity of topical preservative-free methylprednisolone and preserved prednisolone in the treatment of acute anterior uveitis. Cornea. 2014;33(4):366-372. doi:10.1097/ ICO.0000000000000039

17. Kallab M, Szegedi S, Hommer N, et al. Topical Low Dose Preservative-Free Hydrocortisone Reduces Signs and Symptoms in Patients with Chronic Dry Eye: A Randomized Clinical Trial. $A d v$ Ther. 2020;37(1):329-341. doi:10.1007/s12325-019-01137-8

18. Jee D, Park M, Lee HJ, Kim MS, Kim EC. Comparison of treatment with preservative-free versus preserved sodium hyaluronate $0.1 \%$ and fluorometholone $0.1 \%$ eyedrops after cataract surgery in patients with preexisting dry-eye syndrome. J Cataract Refract Surg. 2015;41 (4):756-763. doi:10.1016/j.jcrs.2014.11.034

19. Allam RSHM, Ahmed RA. Evaluation of the lower punctum parameters and morphology using spectral domain anterior segment optical coherence tomography. J Ophthalmol. 2015;2015.

20. Timlin H, Keane P, Day A, Abdullah M, Ezra D. Characterisation of the Lacrimal punctum using spectral domain anterior segment optical coherence tomography: an exploratory study. Invest Ophthalmol Vis Sci. 2014;55(13):2792.
Clinical Ophthalmology

\section{Publish your work in this journal}

Clinical Ophthalmology is an international, peer-reviewed journal covering all subspecialties within ophthalmology. Key topics include: Optometry; Visual science; Pharmacology and drug therapy in eye diseases; Basic Sciences; Primary and Secondary eye care; Patient Safety and Quality of Care Improvements. This journal is indexed on PubMed

\section{Dovepress}

Central and CAS, and is the official journal of The Society of Clinical Ophthalmology (SCO). The manuscript management system is completely online and includes a very quick and fair peer-review system, which is all easy to use. Visit http://www.dovepress.com/ testimonials.php to read real quotes from published authors. 